\title{
ГЕРМЕНЕВТИКА ВОЛИ В ТВОРЧЕСКОЙ ТАЙНЕ ФРИДРИХА ГЁЛЬДЕРЛИНА
}

\section{HERMENEUTICS OF WILL IN THE CREATIVE SECRET OF FRIEDRICH HÖLDERLIN \\ V. Gilmanov \\ L. Prikhozhaya}

Summary: The work raises the problem of the creative secret of Hölderlin, its connection with the problem of the cultural code of Germany. Based on the essence of the poet, complex discourses are considered that are related to the hermeneutic key for understanding the mystery of Hölderlin. An attempt is made to interpret one of the mysteries in his work, reflected in the novel «Hyperion». The conclusion is drawn about the action in this novel and other works of Hölderlin. The interpretation of the secret of Hölderlin from the standpoint of some theories of Russian cosmism is carried out. Hölderlin's thesis is emphasized in his letter to his brother that "Kant is the Moses of our people".

Keywords: myth, numinous, freemasonry, ether, will, poetry.
Гильманов Владимир Хамитович

Д.филол.н., профессор, Балтийский федеральный университет им. Иммануила Канта, г. Калининград gilmanov.wladimir@rambler.ru

Прихожая Лилия Ивановна

К.филол.н., дочент, Балтийский федеральный университет им. Иммануила Канта, г. Калининград lilia.uni@mail.ru

Аннотация: В работе ставится проблема творческой тайны Гёльдерлина, его связи с проблемой культурного кода Германии. Исходя из сущности поэта рассматриваются сложные дискурсы, имеющие отношение к герменевтическому ключу для понимания тайны Гёльдерлина. Предпринимается попытка толкования одной из загадок в его творчестве, отразившейся в романе «Гиперион». Делается вывод о действии в этом романе и других произведениях Гёльдерлина. Проводится интерпретация тайны Гёльдерлина с позиции некоторых теорий русского космизма. Акцентируется тезис Гёльдерлина в его письме к брату о том, что «Кант - Моисей нашего народа».

Ключевые слова: миф, нуминозное, масонство, эфир, воля, поэзия.

\section{ГёльАерлин и «тайная Германия»}

B письме к К.У. Белендорфу от 4 декабря 1801 года Гёльдерлин, сообщая ему о своей радости в связи с предстоящим отъездом во Францию, в Бордо, пишет, что перед ним раскинулся новый мир, более светлый и серьезный, что ему нравится, как устроен этот мир [1]. Но уже в мае 1802 года Гёльдерлин пешком бежит из Бордо. Адресат его письма поэт и драматург Белендорф, скитаясь по свету, покончил жизнь самоубийством, став поводом для одного из загадочных рассказов И. Бобровского. В конце рассказа люди, собравшиеся у могилы поэта, размышляют о том, что можно было бы написать на его могильном камне, припоминая при этом, чем он им запомнился. В конце они признают, что Белендорф так и остался для них непонятной загадкой [2].

Тайна Гёльдерлина не оставляет в покое ни филологов, ни философов, поскольку касается, предельных основ не только поэтического творчества, но и проблемы творчества в целом до эсхатологического предела сотворчества или с Жизнью или со Смертью. Для русской философии творчества характерна христианская эсхатология, суть которой без обиняков сформулирована, например, Н.А. Бердяевым в его работах «Смысл творчества», «Варварство и упадничество», «Новое средневековье» и т.д. [3].

В этой связи идейно-творческая феноменология
Гёльдерлина и ее потаенные истоки продолжают оставаться герменевтическим вызовом, особенно для немецкой культуры с ее для нее самой таинственной двойственностью, о которой в своей работе «Гёльдерлин и немцы», вышедшей накануне его гибели в первой мировой войне, пишет Норберт фон Хеллинграт [4]. К таким произведениям он относит, прежде всего, творения Гёльдерлина. Необходимо отметить, что Гёльдерлин был почти забыт, возможно, по причине довольно прохладной оценки его творчества со стороны Гёте, который остался равнодушен к его произведениям, что явствует из его переписки с Шиллером. Даже простой поверхностный анализ этой переписки показывает, насколько небрежно и без интереса его отношение к 27-летнему автору, испытывающему удушливую робость в присутствии Гете. Гете отзывается о работах Гёльдерлина «не совсем неблагожелательно» и даже не возражает против намерения Шиллера опубликовать эти стихи в «Альманахе муз» и в журнале «Оры» [5].

То, насколько тягостной оказалась для Гёльдерлина его встреча с Гете в августе 1797 года, свидетельствует то, что он, пообещав Шиллеру еще до приезда во Франкфурт написать о ней, не выполнил этого обещания. Взаимное отчуждение Гете и Гёльдерлина можно толковать и как духовную идиосинкразию двух разных онтологий, что возвращает нас к тезису Хеллинграта в его работе «Гёльдерлин и немцы» о «странной двойственности, являющейся сущностью и загадкой немецкого» духа [4]. 


\section{Миф и нуминозное}

Один из возможных подходов к объяснению не только психологического, но и онтологического конфликта между Гёльдерлином и Гете - это миф, а точнее - разность онтологий, лежащих в основе их отношения к мифу. Для Гете миф - это результат поэтической фантазии и воображения, действующими в согласии с творящей и организующей силой природы. В этой связи поэзия и естествознание родственны друг другу, поэтому в стремлении проникнуться вечными идеями божественной природы, дирижирующими как природным, так и художественным творчеством, Гете - поклонник Спинозы - обращается к изучению прафеноменов и их метаморфоз в природе, поэзии и человеке. Эта теория мифа Гете отражена не только в его теоретических работах, но и в его поэзии, например, в таких стихотворениях как «Метаморфоза растений», «Метаморфоза животных», «Первоглаголы. Учение орфиков» и других.

В мифической тайне Гёльдерлина основное место занимает греческий миф [6]. Отличие Гёльдерлина от Гете, изложено в теории мифа К. Хюбнера, в которой именно он выбран как живая персонификация «истины мифа». По Хюбнеру, миф как «система мышления и опыта» не следует смешивать с мифологией, основой которой является использование мифа в литературных или иных целях: миф - это система особой реальности, именуемой им следом за Рудольфом Отто «нуминозной». Нумены - это энергийные знаки высших сил, конституирующих для человека предметность мира как единства идеального и материального [7].

\section{«...тайное в свободе»}

Обращаясь к вопросу о нуминозной силе в мифе, Хюбнер затрагивает одну из самых таинственных проблем эзотерического гнозиса, без учета которой вряд ли возможно адекватное понимание философской и художественной феноменологии германского духа в «эпоху Гете» и в романтизме: это - проблема «середины», а точнее - «магического посредника», действующего в этой середине. В настоящее время в самой Германии существует обширная научно-исследовательская литература, посвященная масонству, включая его активность в Тюрингии, в таких городах как Гота, Йена, Веймар и другие. Тесная связь масонства с оккультизмом и магизмом, теософией и антропософией позволяет, однако, основываясь на доступные источники утверждать, что в конечном итоге «тайна свободы» имеет отношение к выбору между двумя аспектами силы, именуемыми как «электрический vs жизненный, воинственный vs сотрудничающий. Эти два аспекта соответствуют Nahash (змею) и Деве» [8]. Гёльдерлин не мог не вращаться в кругах, имеющих прямое отношение к тайным обществам, поскольку большинство из тех, с кем он имел тесные связи - Шиллер,
Шеллинг, Гегель, Синклер и другие - были масонами.

«Не вызывает сомнения, - пишут современные исследователи масонства И. Бергер и К.-Ю. Грюн, - что в 1790-е и 1800-е гг. в Веймаре (-Йене) сложилась особая атмосфера литературно-эстетической и научно-философской активности, обусловленная, прежде всего, сотрудничеством Гете и Шиллера, произведениями Виланда и Гердера, а также натурфилософскими и идеалистическими изысканиями в проектировании мира» [9]. Вряд ли возможно, обращаясь к творчеству Гете, Шиллера и других, включая Гёльдерлина, найти верный герменевтический ключ к их пониманию, не учитывая телеологию тайных организаций, с которыми они были связаны [10]. Как известно, Кант не изменил свое положительное отношение к Французской революции до конца жизни, в отличие от Гете и Шиллера, разочаровавшихся в ней, хотя веймарские классики были активными участниками тайных обществ, включая ложу «Амалия» в Веймаре.

Отметим, однако, что поднятая выше, в контексте масонства, проблема нуминозной силы важна для учета ее действия в самой сложной для прямого понимания границы, обозначенной Кантом как граница «трансцендентальной видимости», что одновременно имеет отношение к тайне художественного воображения. Вряд ли можно сомневаться, что Гёльдерлин, взятый под опеку Шиллером, тоже вначале рассматривался как возможный кандидат в «братья», о чем свидетельствует, например, замечание Шиллера в письме к Гете от 17 августа 1797 года, где он напрямую объясняет, что, несмотря на сомнение в талантах двух своих протеже Гёльдерлина и Шмидта, он намерен как можно дольше их опекать, чтобы выяснить «годятся ли они для чего-нибудь или нет» [5]. И Гёльдерлин ясно осознает, насколько его судьба зависит от участия Шиллера, включая и материальную сторону, поэтому его письма к Шиллеру проникнуты каким-то болезненным чувством, проявившимся и при его встрече с Гете. Но Гёльдерлин ли - в тайне борьбе с гением Шиллера - или «некая сила», которая прорывается в его исповедальный нарратив в романе «Гиперион»? С нашей точки зрения, тайна этой «некой силы» является ключевой как для понимания Гёльдерлина, так и «тайной Германии» в ее мистической раздвоенности, которая до сих пор не оставляет в покое самих немцев, включая известного современного ученого Дитера Борхмайера с его вопросом, ставшим названием большой книги «Что значит немецкое? Нация в поисках себя» [11]. И может ли Гёльдерлин помочь ответить на вопрос?

\section{Аркан Солнша}

Проникновение в тайну Гёльдерлина предполагает учет большого числа разнородных дискурсов, включая те, которых, как правило, избегают исследователи, например, упомянутое выше масонство в его связи с 
гностицизмом и герметизмом, которые следует иметь в виду, обращаясь к творчеству поэтов и философов. На основании изучения так называемых «бернских рукописей» Гегеля известный немецкий ученый Георг Лукач пришел к выводу о родстве идей «новой религии» у Гёльдерлина и Гегеля с основным представлением о боге как «архитекторе мира» в масонстве, в частности, с культом «верховного существа», провозглашенным Робеспьером [12]. В отличие от Гёльдерлина, искавшего духовную силу для «спасения отчизны» в мифе, Гегель считает, что «истина мифа» получает свое завершение в философии. Гегель дает трансцендентальное обоснование мифа, согласно которому любой миф содержит в себе формы сознания, обладающие априорной необходимостью [13]. Однако важно учесть, что этот намеченный в мифе антропоцентризм снимается в диалектике Гегеля исходным принципом истории как движения абсолютного духа, опредмечивающего себя, в том числе, в развитии сознания.

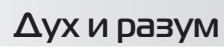

Судя по большому числу публикаций последнего времени, понятие духа вновь обретает тот смысл, который, преодолевая сциентистское искушение тотальным имманентизмом, приближается к границе, разделяющей христианство с его догмой о Духе Святом и масонствующий панлогизм с оккультной подосновой абсолютного духа, за которым маячит понятие бога без имени. Можно упомянуть сенсационную книгу профессора математической физики Франка Типлера «Физика бессмертия» [14]. Проблемой духа и природы занимается видный ученый Грегори Бейтсон, опубликовавший работы с характерным названием «Экология духа. Антропологические, психологические, биологические и эпистемологические перспективы» [15] или «Дух и природа. Необходимое единство» [16]. Среди других работ выделим книгу Йорга Штаркмута «Возникновение реальности», в которой одна из глав носит название «Дух как творец. Роль сознания при возникновении реальности» [17]. Попытки спасения метанарраций в этих работах предпринимаются или в ключе физикализма или с опорой на дисциплину философии трансцендентального субъекта Канта. Гёльдерлин тоже уделил Канту определенное внимание, скорей всего, по совету Шиллера.

Одним из решающих ключей к тайне мифа Гёльдерлина является его обращение к мифической сущности, именем которого назван его роман «Гиперион». Прямо или косвенно это имя связано с Аполлионом, которого вполне можно рассматривать как изотоп Аполлона, то есть как трансмутацию бога солнечного ума в ангелагубителя. В.И. Иванов считает, что начиная с древнего человека люди пытались назвать солнце иначе, чтобы ознаменовать его ближе и правдивее, восходя, таким образом, от менее к более субстанциальному позна- нию вещи божественной» [18]. В работе В. Иванова содержится семиотический код всего нуминозного мифа о Гиперионе, ставшего судьбой Гёльдерлина, который стремился «к более субстанциальному познанию вещи божественной».

\section{«...боги взрастили меня»}

С точки зрения эстетической теории, реализуемой Гёльдерлином в его мифе, она, с одной стороны, близка к Гете с его уравнением миф как поэзия и поэзия как природа, но, с другой, оказывается ближе всего философии тождества Шеллинга, согласно которой «мифология имеет не аллегорический, а таутегорический характер» [19]. То есть, по Шеллингу, миф есть не «символ, сравненье», как у Гете, а результат «необходимого (применительно к сознанию) процесса», вызываемого и реализуемого не демонической силой природы как causa sui, как у Гёте, а «теологической силой» [20]. Но именно это положение, как и другое, сближает Гёльдерлина с Шеллингом, с которым он дружил со времен учебы в Тюбингене и которого в письме, написанном в июле 1799 года, приглашал к участию в своем литературно-философском журнале, который, однако, так и не вышел в свет

В этой связи феномен Гёльдерлина важен не только как эстетическая тайна, но и как космологическая, возвращающая к вопросу Канта «Что такое человек?» и ставящая под сомнение объективистский идеал современной науки. Так, видный современный философ Д. Чалмерс невольно ставит проблему «магического посредника» в глубинах человеческой психики, задающего «каузальный поток» в физическом мире [21].

\section{Воля к форме}

Как это не парадоксально, но нам представляется, что именно герменевтика искусства Горского и Сетницкого позволяет в какой-то степени смысловой адекватности приблизиться к творческой тайне Гёльдерлина, прежде всего, к нуминозной тайне его романа «Гиперион». При этом важно учесть, что эти почти забытые космисты, открыв в искусстве отражение усиления динамики того, что они называют «смертобожничеством», главным догматом которого является положение о «непобедимости и неодолимости смерти» [22]. Несмотря на то, что идеи обоих русских космистов не были приняты ни в стандарте научного идеала естествознания, ни в православной догматике по причине их связи с учением Н.Н. Федорова, они оказываются изоморфными идейном комплексу, сформировавшемуся в эстетических теориях литературно-художественного формализма, прежде всего в традиции англо-американской «новой критики», в частности в концепции «органической формы», восходящей к С. Кольриджу, и концепции «точки зрения», восходящей к Г. Джеймсу [23]. 


\section{Искусство как опасность}

В своей книге «Трагическая история литературы» Вальтер Мушг пишет, что «все великие поэты романтизма пережили свое искусство как смертельную опасность» [24], поскольку в их творчестве прямо или косвенно присутствовало «наследие магической религиозности», ставившее их перед лицом экзистенциальной открытости для вдохновения Неба или Ада. Гете раскрыл тайну своего вдохновения не только в трагедии «Фауст», но и в многочисленных откровениях в разговорах с И.П. Эккерманом, связав тайну поэзии и музыки как высшего вида искусства с демоническим, каковое, согласно ему, всеобъемлющим образом определяет и мировой процесс, превращая политику в рок [25].

Следует упомянуть, как Гёльдерлин, будучи уже во мраке безумия, то есть в состоянии «исчезновения имени» как самого, так и бога, которому он посвятил миф своей жизни, нередко с наслаждением перечитывал в своей башне собственный роман «Гиперион», восклицая при этом: «Как это прекрасно!». Так кто же все-таки ауктор романа, сделавший автора своей «точкой зрения» на реальность, трансформированную, по Бодрийяру, в симулятивную гиперреальность с ее эффектом исчезновения того, чему молился поэт Гёльдерлин и что до появления теории Эйнштейна принималось во внимание и физиками - мировой эфир?

\section{«Кенигсбергские предупрежления»}

Почти все исследователи отмечают, что в поздней лирике Гёльдерлина возникают образы Нового Завета, доводя его до Патмоса, где Иоанну Богослову явилось Откровение о судьбах мира при Втором Пришествии. Поэт будто подтверждает это, начиная свой «Патмос» так: «Близок бог / И непостижим. / Где опасность, однако, / Там и спасенье». Но его «Христос» - это не Христос Нового Завета: его трактовка близка, как уже было указано выше, к гностическим толкованиям, которым следовали масонство или протестантская неология, смешивая Христа с другими античными богами. В этом заключена одна из самых больших опасностей для тех, кто пытается достичь Христа в гносеологии «разумной определенности» [26]. Гёльдерлин как «поэт поэтов» подтверждает правомерность этого «кенигсбергского предупреждения» в лице Канта и Гамана. Предупреждение Канта касается, прежде всего, опасности «Я, или Он, или Оно (вещь), которое мыслит, представляет не что иное, как трансцендентальный субъект мысли [27]. Предупреждение Гамана касается того, что в проблеме веры, независимо от ее объекта всегда присутствуют Небо и Ад. Косвенно опасность поэтической соляристики Гёльдерлина отражена в антропософии Р. Штейнера, назвавшего главным противником Христа в мировом развитии «солнечного демона» с именем Сорат [28].
Учитывая то, что Гёльдерлин не просто обращается к мифологии, а создает свой собственный миф, наполняя его «солярной энергией» новой субстанциальности, которая разрушила эфирную субстанцию Диотимы, мы при close reading его творений становимся свидетелями поэтического самоубийства его разума под воздействием игры художественного воображения, инспирированного нумизной силой в глубинах его «обостренной субъективности» (Шиллер).

\section{Кант как пово $\Delta$ мя «свяшенной трезвости»}

В истории германского духа Гёльдерлин оказывается одним из важнейших поэтических симптомов в истории духовно-политических перекрестков Германии после явления Лютера, отвергнувшего католический принцип Natura vulnerata not deleta = Природа ранена, но не погибла. Эта «честность» находит определенное подтверждение в диагнозе Канта об «изначальном зле в человеческой природе» [29]. Но кантовский призыв к «выходу из состояния собственного несовершенства» есть, по сути, та «священная трезвость», которая, исходя из диагноза о «радикальном зле», ищет путь к преодолению его. Этот путь оказывается связан с тем, к чему все время молитвенно обращался Гёльдерлин - мировой эфир. То, насколько важное место концепция эфира занимала в творчестве Канта, доказывает С.В. Луговой в своей работе «Магистерская диссертация И. Канта «Об огне» и трансформация его представлений об эфирной материи» [30]. Независимо от того, с чем следует соотносить кантовское представление об эфире - с физикотеологией в духе Ньютона и М. Кнутцена, учителя Канта, или с энтелехией в дискурсе античной философии, оно имеет отношение к вопросу о всепроникающем посреднике, который так важен и для Гёльдерлина. Конечно, Гёльдерлин толковал эфир иначе, чем Кант, и в этом толковании распознаются, с одной стороны, влияние Пиндара, гимны которого он переводил на немецкий, с другой, модные среди романтиков идеи «магического посредника» вплоть до учения о «животном магнетизме» в духе Ф.А. Месмера.

Особую «немецкую инаковость» Канта отметил С.Н. Булгаков. По Булгакову, «религиозная заслуга» Канта, каковую Кант сам не заметил, заключается в его довольно точном описании «интуиции тварности» мира, что исключает тезис Спинозы о природе как causa sui, ставший основой романтического панпсихизма с его доверием поэтической фантазии и панлогизма Гегеля с его доверием силе мирового духа. Эта невольная заслуга Канта связана с его космологической антиномией о причинности и свободе. Подробно анализируя эту антиномию, Булгаков, критикуя рационалистическую философию за отказ от принципа тварности как ложного, указывает на внутреннюю логическую ошибку рациональной дискурсивности [31]. Этот ход мыслей Булгакова близок инту- 
итивизму Анри Бергсона, который также уделяет Канту большое внимание, стремясь преодолеть трансцендентальную эстетику Канта. Исходя из того, что разум «характеризуется природным непониманием жизни», находясь в «заколдованном круге» своих проекций, Бергсон призывает во имя жизни «действием разбить этот круг», для чего «нужно смело броситься вперед и актом воли вывести интеллект за его пределы» [32].

В контексте нашей работы важен затронутый аспект воли, выводящей разум за его пределы, учитывая опыт «власти какой-то силы», побудившей Гипериона разрушить мир Диотимы, а затем сознание самого Гёльдерлина. Власть этой силы благословил Ницше, тоже поплатившийся безумием, причем сделал это в невольном признании трансцендентного истока этой силы, предав христианство проклятию в духе Антихриста. В свете философии творчества Бердяева эта сила побуждает к творчеству во имя диавола, реализуя его волю и побуждение к негативной, пустой свободе, к свободе во грехе [3]. В этой связи в истории германского духа Кант с его великой честностью в отношении чистого разума, столкнувшегося с антиномиями, предстает как уникальное явление, поскольку предупреждает о той опасности, жертвой которой стал не только Гёльдерлин, но и многие другие гении культуры [29]. Кант настаивает на категорическом императиве акта нравственной воли, выводящей чистый разум в план практического действия в максиме закона совести. Несмотря на стремление остаться в пределах только разума, Кант в своей «диктатуре совести» все же совершает, по нашему убеждению, акт принесения разума в жертву совести, признавая необходимость примата нравственной логики над формальной. Его моральный ригоризм выступает как призыв противостоять искушениям Фауста, принятым Гете, и «бракосочетанию
Неба и Ада», допущенному У. Блейком. В своем небольшом наброске на тему «Суждение и бытие», написанном во время его пребывания в Йене в 1795 году, он, опираясь на морфологическую структуру немецкого суждения есть в высшем и строжайшем смысле первоистоковое разделение тесно связанных в интеллектуальном созерцании объекта и субъекта, то есть такое разделение, которое только и делает возможным и объект и субъект: перво-разделение. В понятии разделения уже заложено двустороннее взаимоотношение объекта и субъекта друг с другом, а также необходимая предпосылка той целостности, частью которой являются как объект, так и субъект.

Трагедия судьбы и творчества Гёльдерлина доказывает, что его «Я», забывшее даже свое исходное имя и ставшее кем-то, кто требовал называть себя Буонаротти или Скарданелли, вышло за пределы своего разума, как призывает Бергсон, однако в акте той воли, которая не освятила его духовным солнцем истины, а сожгло огнем сразившего его Аполлона. Гёльдерлин - серьезный повод для поиска выхода из оккультной динамики той воли, которая не только привела Германию к краю бездны в двух мировых войнах и национал-социализме, но и инфицировала Россию по причине таинственного «избирательного сродства» двух культур. Культурный код России связан, прежде всего, с тем, что В.С. Непомнящий именует термином «пасхальность» [33], противопоставляя его «рождественской культуре» Запада, которой причастна и Германия. И в динамике этой культуры прямо или косвенно Кант, выступающий как тот, кого в эзотерике именует «Хранителем Порога», то есть представителем суда Совести и учителем в школе Совести, мог бы в самом деле стать «Моисеем» для спасения из того духовного плена, одной из жертв которого стал Гёльдерлин.

\section{ЛИТЕРАТУРА}

1. Гельдерлин. Сочинения. М.: Художественная литература, 1969.

2. Bobrowski J. Gesammelte Werke: in 6 Bdn. Stuttgart: Deutsche Verlags-Anstalt, 1999. B. 4.

3. Бердяев Н.А. Философия творчества, культуры и искусства (в 2 т.). М.: Искусство, 1994. Т. 1.

4. Hellingrath N. Hölderlin und die Deutschen // Zwei Vorträge. München 1922. S. 15 - 48.

5. Briefwechsel zwischen Schiller und Goethe in den Jahren 1794 bis 1805: in 2 Bdn. Goldmann-verlag 2005. B. 1.

6. Гете И.В. Собрание сочинений: в 10 т. М.: Художественная литература, 1975 - 1980.

7. Хюбнер К. Истина мифа. М.: Республика, 1996.

8. Энциклопедия герметической философии. Старшие арканы Таро. СПб.: Алетейя, 1997.

9. Geheime Gesellschaft. Weimar und die deutsche Freimaurerei. München Wien: Carl Hanser, 2002

10. Algermissen K. Freimaurer // Lexikon für Theologie und Kirche. Freiburg, 1960.

11. Borchmeyer D. Was ist deutsch? Die Suche einer Nation nach sich selbst. Berlin: Rowolt, 2017.

12. Lucacs G. Der junge Hegel und die Probleme der kapitalistischen Gesellschaft. Zürich-Wien: Europa Verlag, 1948.

13. Гегель Г.В.Ф. Эстетика: в 4 т. М.: Искусство, 1968.

14. Tipler F. Die Physik der Unsterblichkeit. Moderne Kosmologie, Gott und die Auferstehung der Toten. München: Deutscher Taschenbuch Verlag, 1995.

15. Bateson G. Ökologie des Geistes: anthropologische, psychologische, biologische und epistemologische Perspektiven. Frankfurt am Main: Suhrkamp, 1999.

16. Bateson G. Geist und Natur. Eine notwendige Einheit. Frankfurt am Main: Suhrkamp, 2000. 
17. Starkmuth J. Die Entstehung der Realität. Wie das Bewusstsein die Welt erschafft. München: Random House, 2010.

18. Иванов В.И. Две стихии в современном символизме // Русские философы. Антология. М.: Книжная палата, 1993. С. 212 - 242.

19. Шеллинг Ф. Введение в философию мифологии // Шеллинг Ф. Сочинения: в 2 т. Т. 2. М.: Мысль, 1989. С. 159 - 374.

20. Гильманов В.Х. «Крестовые походы» И. Г. Гамана против Просвещения // Вестник МГУ. Сер.: Философия. 2005. №3. С. 14 - 26.

21. Чалмерс Д. Сознающий ум: в поисках фундаментальной теории. М.: Либроком, 2013.

22. Горский А.К., Сетницкий Н.А. Сочинения. М.: Раритет, 1995.

23. Кольридж С.Т. Избранные труды. М.: Искусство, 1987.

24. Muschg W. Tragische Literaturgeschichte. München: Francke Verlag, 1983.

25. Эккерман И.П. Разговоры с Гете в последние годы его жизни. Ереван: Айастан, 1988.

26. Müller F.V . Unterhaltungen mit Goethe, mit Anmerkungen versehen und herausgegeben von R. Grumach. Weimar, 1982.

27. Кант И. Собр. соч.: В 8 т. Юбилейное издание 1794 - 1994 / Под ред. А. В. Гулыги. М.: Изд-во «Чоро», 1994.

28. ProkofieffS. Die Begegnung mit dem Bösen und seine Überwindung in der Geisteswissenschaft. Der Grundstein des Guten. Dornach: Verlag am Goetheanum, 2015.

29. Kunst H. Martin Luther. Ein Handbuch. Gross-Oesingen, 1993.

30. Луговой С.В. Магистерская диссертация И. Канта «0б огне» и трансформация его представлений об эфирной материи // Кантовский сборник. - 2019. T. 38, № 2. C. $7-30$.

31. Булгаков С.Н. Свет невечерний: созерцания и умозрения. М.: Республика, 1994.

32. Бергсон А. Творческая эволюция. Материя и память. Минск: Харвест, 1999.

33. Непомнящий В.С. Удерживающий теперь. Феномен Пушкина и исторический жребий России. Новый мир. 1996. №5.

(с Гильманов Владимир Хамитович (gilmanov.wladimir@rambler.ru), Прихожая Лилия Ивановна (lilia.uni@mail.ru)

Журнал «Современная наука: актуальные проблемы теории и практики»

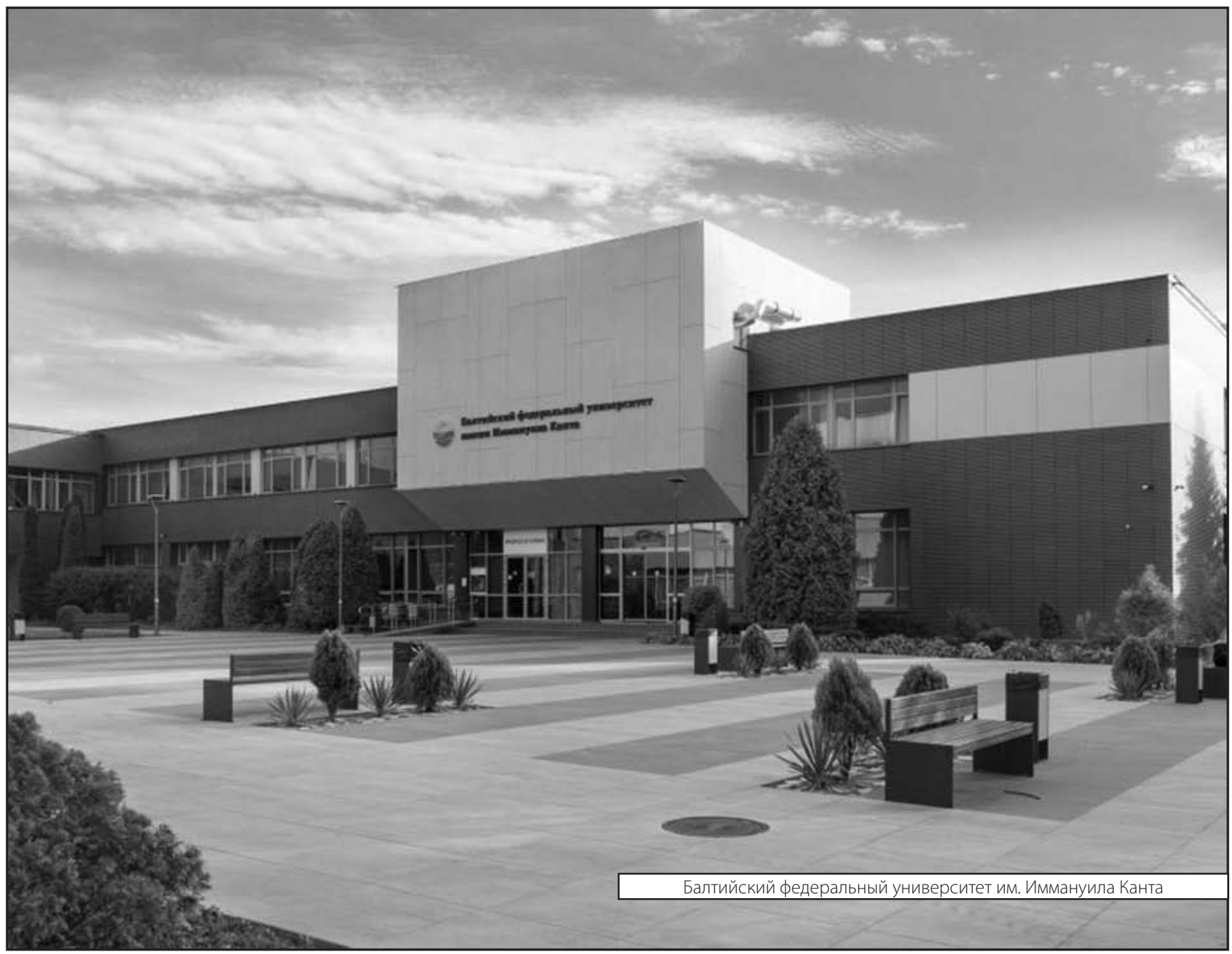

